advanced. Before explaining this theory $I$ will allude to a phenomenon which is apparent in nearly every large exposure of flint-bearing chalk. Seams of flint, often not more than an inch in thichness (sometimes much less), may be seen in the chalk, running at almost right angles to the lines of stratification. From these seams it is possible to detach slabs some feet in superficial area, but only an inch or so in thickness. Now, I ask any person who has the slightest knowledge of the nature of deposition and stratification, whether such a mass as I have described could have been formed at the bottom of the sea round a nucleus of any description, and then have been deposited with the chalk in such a position, viz. at a considerable angle to the lines of stratification. I think that the answer will be in the negative, and that we must have some other theory than that held by Dr. Bowerbank to account for the presence of, at any rate, such masses as these. You have probably noticed the seams, to which I allude, yourself, as they are abundant every where along the south-western coast of England. My attention was first drawn to them in the cliffs between Brighton and Rottingdean, where many and striking examples may be seen. The only theory which can explain these occurrences, and which is sound as far as I can see in other respects, was held, I believe, by the late Professor Henslow, who considered that the chalk flints had been formed after the deposition of the calcareous stratum in which they are found, during its elevation from the sea, by the percolation and concentration of water, highly charged with silica, into cavities left by the decomposition of animal and vegetable matters which had been enclosed. In the process of drying, fissures would naturally form in the chalk, in which the siliceous water could accumulate and leave its deposit of flint, in the same manner as it had accumulated and formed "nodular" masses in the cavities left by the decomposition of sponges, echino-

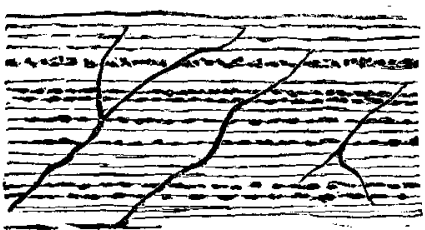
derms, mollusks, etc. I think it is also probable that the gases formed by the decomposition of these organic bodies would enlarge the cavities formed in the yielding chalk; and might not some chemical affinity or exchange also have assisted in the elimination of the siliceous particles from the water?

I should be glad to hear from yourself or correspondents, either facts which will tend to support this theory, or some other hypothesis which will better explain the occurrence of these continuous seams of flint. I enclose you a sketch of the cliff with flint seams, and remain,

September 8th, 1861.

Yours, ete,

Silex.

\title{
The Red Sandstone Blocks of Dunmanuay.
}

Sir,-The beautiful representation of the Old Red Sandstone block of Dunmanway, county Cork (given at page 248, 'Geologist' for July) gives rise to the following suggestions :-

Dunmanway's Old Red Sandstone blocks stand forth as rocks

Of water-markings; not rubs and jolts of ice-blocks ;

Water went round to mark them. 
The ripple-marks left by undulating waters

On limestones in Lake Killarney, and other quarters, May still be seen in progress.

Yours faithfully, A Subscriber.

\section{6th August, 1862.}

[If our correspondent is not pleased with his communication being set up by our compositor as a poetical effusion, he has no one to blame but himself; for, not sending us, in confidence, his name and address, we could neither send him a proof nor ask his instructions. We are continually annoyed by this reprehensible conduct, and many things worth printing are often, for this reason, consigned to our waste-paper basket. The post-mark on this communication is Ryde, but we should only give the Dead Letter officers trouble if we posted a letter "To Subseriber" there. It would be a worse address than the memorable "John Smith, England."-Fin. GEoL.]

\section{The Kirkdale Cavern.}

Sir,- In the September number of 'Macmillan's Magazine ' there is an article by Mr. Jolin Taylor, concerning this place, upon which, as I take it to be a very important one (thus greatly differing from the majority of geological papers, which are combinations of the most obvious facts and the most unobvious speculations), I am desirous of making a few observations. That it presents an agreeable contrast to the views of some of "our best authorities" in geology, no candid person can but admit; but, at the same time, I look upon it as perhaps the commencement of new inquiries, which probably will effect the demolition of similar irrational and far-fetched explanations.

That any individual could consider the one in question, and yet maintain the doctrine of Buckland, could, I think, only be accounted for on the ground of faith in this distinguished geologist,- the facts alluded to by Mr. Taylor being absolutely crucial as regards the conclusion drawn from them. We have here an example of an apparently geological phenomenon which is really an historical one, and of the utility which the knowledge of ancient customs is in the explanation of physical phenomena. In the present case, without this knowledge the explanation would have been only a speculation; but as the explanatory circumstance is known to have been a fact, and it is not possible otherwise to account for the phenomenon, there is as much certainty as can be obtained concerning any unseen phenomena. In this sense the conclusion is warranted, or crucial, from the facts brought forward. I have here, of course, presumed that the alleged facts are such, concerning which, as far as I can understand, no discussion can be raised.

\section{J. Alexander Davies.}

[We are sorry to read the opinion formed by our correspondent of the antiquated, absurd, and ignorant article in 'Macmillan's Magazine.' Want of space prevents comments on our part non it in the present number, but we shall refer to the subject again. Two excellent articles in the 'Londou Revicw' may, in the interim, be perused with advantage by Mr. Davies and those who concur in his appreciation of Mr. Taylor's untenable article.]

\section{GEOLOGICAL NOTES IN THE GREAT EXHIBITION.}

ITALY.-The Natural History Museum of the Royal University of Pisa exhibits the following plaster and wax models of fossils :-Mastodon Avernensis (jaws and separate teeth); Elephas meridionalis (jaws, part of upper jaw, teeth); Hippopotamus major (part of jaw, teeth); Rhinoceros Etruscus (skull, part of jaw, part of upper jaw); Lutra Campani (almost 